Tersedia online di: http://ejournal-balitbang.kkp.go.id/index.php/JP
e-mail:jurnalpari@gmail.com
JURNAL PARI
Volume 4 Nomor 1 Juli 2018
p-ISSN: 2502-0730
e-ISSN : 2549-0133

\title{
TINGKAT KETERSEDIAAN KOLEKSI PERPUSTAKAAN BBRBLPP MELALUI ANALISIS SITASI KARYA TULIS ILMIAH PENELITI BBRBLPP TAHUN 2016-2017
}

\author{
KETUT MASIANI \\ Balai Besar Riset Budidaya Laut dan Penyuluhan Perikanan (BBRBLPP) \\ Diterima tanggal : 19 Februari 2018 Diterima setelah perbaikan : 18 Mei 2018 \\ disetujui terbit : 22 Juni 2018
}

\begin{abstract}
ABSTRAK
Ketersedian koleksi yang berkualitas dan mampu memenuhi kebutuhan pengguna merupakan bagian yang penting diperhatikan perpustakaan. Tujuan kajian ini adalah untuk mengetahui tingkat ketersedian koleksi yang ada diperpustakaan Balai Besar Riset Budidaya Laut dan Penyuluhan Perikanan (BBRBLPP). Evaluasi dilakukan dengan melakukan kajian terhadap daftar pustaka/ sumber acuan yang digunakan peneliti dalam penulisan karya tulis ilmiah (KTI) tahun 2016 dan 2017. Penghitungan dilakukan dengan menggunakan rumus persentase Kerlingger. Hasil analisa menunjukkan bahwa dalam kurun waktu tahun 2016-2017 publikasi yang digunakan sebagai acuan yaitu jurnal sebanyak $65 \%$, buku $22 \%$ serta prosiding $13 \%$. Namun demikian, tidak semua sumber acuan yang digunakan dalam penulisan KTI tersedia di perpustakaan BBRBLPP. Dari total jurnal yang digunakan untuk KTI, hanya $43 \%$ yang tersedia, demikian pula dengan ketersediaan buku $57 \%$, dan ketersediaan prosiding dengan kategori paling tinggi yaitu $84 \%$.
\end{abstract}

Kata kunci: Koleksi, ketersedian, referensi

\begin{abstract}
The availability of a quality collection that meet the needs of users is an important part of the library. The purpose of this study is to determine the availability of existing collections in the the Institute for Mariculture Research and Fisheries Extension (IMFRAFE) Library. Evaluation was done by conducting a study of bibliography / reference sources used by researchers in their scientific papers from 2016 to 2017. Calculation was done by using Kerlingger percentage formula. The result showed that in the period of 2016-2017 the publication used as the reference is the journal as much as $65 \%$, book $22 \%$ and proceedings $13 \%$. However, not all of reference sources used in scientific paper are available in the IMRAFE library. From the total of used journals, only $43 \%$ are available, as well as $57 \%$ of books, and availability of proceedings with the highest category of $84 \%$.
\end{abstract}

Keywords: Collection, availability, reference 


\section{PENDAHULUAN}

Perpustakaan merupakan salah satu sumber referensi atau pusat informasi bagi pemustakanya. Penyediaan informasi merupakan salah satu tugas pokok perpustakaan. Pada perpustakaan khusus, tugas pokok utamanya adalah menyediakan informasi yang mendukung kegiatan lembaga induknya. Menurut Basuki (1991) perpustakaan khusus adalah perpustakaan yang diselenggarakan oleh sebuah dapartemen, lembaga, lembaga negara, lembaga penelitian, organisasi massa, militer, industri maupun perusahaan swasta yang bertugas untuk melayani keperluan badan tersebut dengan menyediakan koleksi buku untuk para ahli dan penelitian yang tergabung pada badan tertentu dan memberi keterangan biografi yang cepat dan tepat serta mengadakan penelusuran literatur atas permintaan. Keberhasilan pelayanan perpustakaan khusus dapat dilihat dari besar tidaknya sumber informasi yang dimanfaatkan oleh pengguna di lembaganya. Menurut Soetminah (1992) fungsi perpustakaan khusus adalah sebagai pusat referal dan penelitian serta untuk memperlancar pelaksanaan tugas instansi yang bersangkutan. Kegiatan penelitian dan penulisan karya tulis ilmiah membutuhkan banyak koleksi sebagai bahan referensinya sehingga keberadaan literatur dalam kegiatan penelitian memiliki peranan yang sangat penting. Perpustakaan khusus wajib menyediakan koleksi yang dibutuhkan penggunanya sehingga segala kebutuhan informasi yang dibutuhkan oleh pengguna dapat dilayani. Keberadaan literatur merupakan bagian yang sangat penting dan dibutuhkan dalam kegiatan penelitian (Surata, 1997). Pendapat ini menekankan bahwa koleksi di perpustakaan khusus merupakan bagian yang sangat penting karena koleksi di perpustakaan merupakan salah satu sumber informasi, sumber referensi dalam kegiatan penelitian yang dilakukan oleh peneliti. Perpustakaan khusus perlu melakukan penyediaan informasi yang terbaru secara cepat dan tepat. Infomasi yang terbaru akan mampu memberikan ideide yang dapat memunculkan inovasi-inovasi terbaru.

\section{DESKRIPSI PERMASALAHAN}

Perpustakaan BBRBLPP merupakan perpustakaan khusus yang memiliki tugas pokok dan fungsi mendukung tugas pokok dan fungsi BBRBLPP salah satunya adalah kegiatan penelitian. Untuk mengetahui tingkat ketersedian koleksi perpustakaan perlu dilakukan pengkajian mengenai ketersedian koleksi. Tujuan dalam pengkajian ini adalah untuk mengetahui tingkat ketersediaan koleksi yang ada di perpustakaan BBRBLPP

\section{TINJAUAN PUSTAKA}

Dalam panduan perpustakaan khusus Perpustakaan Nasional Republik Indonesia (1992) dinyatakan bahwa koleksi perpustakaan khusus tidak terletak pada banyaknya jumlah bahan pustaka atau jenis terbitan lainnya melainkan ditekankan pada aspek kualitas koleksinya, agar dapat mendukung jasa penyebaran informasi muktahir serta penelusuran informasi. Koleksi perpustakaan khusus secara umum didominasi oleh koleksi yang memuat informasi yang terakit dan mendukung tupoksi dari lembaga induknya. Perpustakaan perlu menyediakan koleksi yang sesuai dengan kebutuhan pengguna yang dapat menjadi referensi dan sumber-sumber ide untuk melahirkan inovasi terbaru bagi penggunanya. (Lasa, 2005 ) menekankan bahwa koleksi yang disediakan diperpustakaan merupakan koleksi yang memuat bahan informasi, yang mampu menunjang kegiatan keilmuan anggota potensial dan sesuai dengan visi dan misi lembaga induknya.

\section{Ketersediaan koleksi}

Undang-Undang Republik Indonesia Nomor 43 Tahun 2007 tentang Perpustakaan menyebutkan koleksi perpustakaan adalah semua informasi dalam bentuk karya tulis, karya cetak, dan/atau karya rekam dalam berbagai media yang mempunyai nilai pendidikan, yang dihimpun, diolah, dan dilayankan. Perpustakaan memiliki kewajiban untuk menyediakan koleksi yang dibutuhkan oleh penggunanya. Ketersedian koleksi merupakan salah satu unsur penting dalam kelancaran pelayanan perputakaan kepada penggunanya. Ketersediaan koleksi perpustakaan adalah sejumlah koleksi atau bahan pustaka yang dimiliki oleh suatu perpustakaan dan cukup memadai jumlah koleksinya dan koleksi tersebut disediakan agar dapat dimanfaatkan oleh pengguna perpustakaan tersebut (Sutarno, 2007). Tersedianya koleksi yang memadai mampu mewujudkan pemanfataan koleksi yang optimal dan mampu menjadi daya tarik perpustakaan sebaga sumber informasi. Beberapa hal yang perlu diperhatikan dalam melakukan ketersediaan koleksi perpustakaan (Sutarno dalam Azrin, 2017) antara lain:

1. Kerelevanan, koleksi hendaknya disesuaikan dengan kebutuhan pengguna perpustakaan.

2. Berorientasi kepada pengguna perpustakaan.

3. Kelengkapan koleksi.

4. Kemutakhiran koleksi. 


\section{Evaluasi ketersediaan koleksi}

Evaluasi ketersedian koleksi dilakukan untuk mengetahui koleksi-koleksi yang tersedia diperpustakaan yang digunakan sebagai acuan oleh peneliti dalam penulisan karya tulis ilmiahnya. Ketersediaan koleksi merupakan indikator kualitas pelayanan perpustakaan dalam pelayanan terhadap pengguna perpustakaan. Kegiatan evauasi ketersedaain koleksi perlu dilakukan untuk mengetahui kebutuhan dan tingkat kersediaan koleksi yang ada di perpustakaan Menurut Yulia, (1993), Perpustakaan melakukan evaluasi koleksi bertujuan untuk

a. Mengetahui ruang lingkup dan kedalaman koleksi

b. Menyesuaikan koleksi dengan tujuan dan program lembaga yang membawahinya

c. Mengikuti perubahan perkembangan sosial dan budaya, ilmu pengetahuan dan teknologi

d. Meningkatkan nilai informasi

e. Mengetahui kekuatan dan kelemahan koleksi

f. Menyesuaikan kebijakan penyiangan koleksi

\section{Analisis Sitiran}

Analisis sitiran merupakan sebagai suatu cara perhitungan terhadap karya tulis yang disitir oleh pengarang yang mempublikasikan karyanya pada waktu setelahnya (Lasa, 1990). Kegiatan analisis sitiran ini dapat digunakan untuk mengetahui sumber referensi yang digunakan penulis dalam menghasilkan karya tulisnya. Analisa lain yang dapat memanfaatkan analisi sitiran ini yaitu analisa untuk mengetahui ketersedian koleksi. Menurut Broadus (2007) metode dasar dari kajian sitiran adalah penghitungan terhadap karya yang disitir oleh para pengarang yang digunakan untuk mempersiapkan karya tulisnya atau paling tidak yang mempunyai andil dalam penyusunan karya tulis tersebut. Analisis sitasi dilakukan dengan menganalisiss daftar acuan yang digunakan oleh penulis di dalam suatu karya tulisnya. Reitz dalam (Istiana, 2007) menyebutkan bahwa sitiran merupakan acuan tertulis dari sebuah karya atau bagian sebuah karya (dapat berupa buku, artikel, disertasi, laporan, komposisi musik dan sebagainya) yang dihasilkan oleh pengarang, penyunting, komposer dan sebagainya, yang secara jelas mengidentifikasi suatu dokumen, di mana karya itu diperoleh.

Penggunaan metode analisis sitasi dalam analisis pemanfaatan koleksi peprustakaan dapat memberikan gambaran tingkat pemanfaatan koleki perpustakaan oleh pengguna/peneliti serta dapat memberikan gambaran tingkah laku penggunaan smber-sumber perpustakaan (Hasiguan, 2005). Secara rinci Lasa
(2009) menyebutkan bahwa studi pustaka melalui sitiran ini akan diperoleh manfaat antara lain:

1. Mengidentifikasi karya-karya inti

2. Mengelompokkan sumber-sumber menurut literatur yang disitir yang memiliki kesamaan

3. Mengetahui jenis-jenis literatur yang digunakan penulis

4. Mengetahui rata-rata pertumbuhan dan keusangan literatur

\section{METODE \\ Sumber Data}

Data yang digunakan dalam pengkajian ini terdiri dari data primer dan dat sekunder. Data primer dalam pengkjian ini diperoleh dari hasil analisis sitasi terhadap karya tulis ilmiah peneliti BBRBLPP yang terbitan tahun 2016-2017. Sedangkan data sekunder diperoleh melalui studi pustaka, baik cetak maupn non cetak yang terkait dengan ketersedian dan pemanfaatan koleksi.

\section{Teknik Pengumpulan Data}

Metode pengambilan sampel yang digunakan dalam penelitian ini adalah total sampling yaitu teknik pengambilan sampel dengan ketentuan bahwa jumlah sampel adalah sama besar seperti halnya jumlah populasi (Sugiyono, 2010).

\section{Teknik Analisis Data}

Analisis data dilakukan melalui analisi daftar pustaka analisis sitiran dari hasil karya tulis ilmiah peneliti BBRBLPP yang diterbitkan tahun 2016-2017 yang termuat dalam prosiding dan jurnal. Ada beberapa langkah dalam teknik analisis sitiran terhadap karya IImiah (Sujana, 2006) yakni sebagai berikut:

1. Mencatat semua bahan pustaka (pengarang, judul, tempat terbit, penerbit, dan tahun terbit) yang dijadikan daftar pustaka pada sejumlah karya ilmiah yang dipilih dijadikan sebagai sampel.

2. Daftar tersebut dicocokkan dengan data katalog perpustakaan.

3. Diketahui berapa persentase dari bahan pustaka yang dirujuk dalam karya ilmiah tersebut tersedia di perpustakaan.

4. Selain itu, dapat diketahui juga jenis koleksi yang banyak digunakan/ dirujuk dan judul jurnal yang paling banyak dirujuk untuk setiap bidang ilmu dari karya ilmiah tersebut

Mengacu pada langkah-langkah diatas dalam pengkajian ini, tahap kegiatan yang dilakukan yaitu: 
1. Pengumpulan Karya Tulis IImiah (KTI) peneliti BBRBLPP yang terbit tahun 2016 dan 2017

2. Mengumpulkan dan mencatat data dari daftar pustaka pada Karya Tulis IImiah

Pencatatan data dilakukan berdasarkan kelompok yang ditetapkan yaitu berdasarkan jenis koleksi dan pembagian berdasarkan ada tidaknya koleksi yang digunakan di perpustakaan. kelompok $A=$ Ada diperpustakaan, $\mathrm{T}=$ Tidak ada di perpustakaan

3. Menganalisis data yang telah dikumpulkan sesuai kebutuhan

Analisa data yang telah dikumpulkan menggunakan rumus persentase Kerlingger (1990) sebagai berikut:

$$
\begin{array}{ll} 
& P \frac{F}{N} x 100 \% \\
\mathrm{P} & =\text { Persentase } \\
\mathrm{F} & =\text { Frekuensi } \\
\mathrm{N} & =\text { Jumlah keseluruhan }
\end{array}
$$

Penafsiran hasil analisa menggunakan persentase yang dikemukakan (Arikunto, 2003) yaitu:

$$
\begin{aligned}
& 81-100 \%=\text { Sangat Tinggi } \\
& 61-80 \%=\text { Tinggi } \\
& 40-60 \%=\text { Sedang } \\
& 21-40 \%=\text { Rendah } \\
& 0-20 \%=\text { Sangat rendah }
\end{aligned}
$$

\section{Penyajian Data}

Hasil analisis data yang telah dilakukan dalam pengkajian ini disajikan dalam bentuk table dan persentase.

\section{HASIL DAN PEMBAHASAN}

Dalam kurun waktu tahun 2016 -2017 terdapat 67 tulisan peneliti BBRBLPP dengan jumlah sitiran sebanyak 1382 sitiran. Rata rata sitiran pada tahun 2016 sebanyak 20 sitiran per judul dan pada tahun 2017 sebanyak 22 sitiran dalam setiap judulya (Tabel 1.)

Tabel 1. Rata-rata Jumlah sitiran dalam publikasi peneliti BRBLPP tahun 2016-2017

\begin{tabular}{|c|c|c|c|}
\hline \multirow{2}{*}{ Tahun } & \multirow{2}{*}{ Jumlah Publikasi } & \multicolumn{2}{|c|}{ Sitiran } \\
\cline { 3 - 4 } & & Jumlah & Rata rata \\
\hline 2016 & 48 & 967 & 20 \\
\hline 2017 & 19 & 415 & 22 \\
\hline Total & $\mathbf{6 7}$ & $\mathbf{1 3 8 2}$ & $\mathbf{2 1}$ \\
\hline
\end{tabular}

Berfungsinya suatu perpustakaan dapat dilihat dari tingkat pelayanan dan keterpakaian koleksi yang dimiliki. BBRBLPP sebagai lembaga riset salah satu bentuk hasil riset yang dilakukan peneliti adalah karya tulis ilmiah. Penulisan karya tulis ilmiah ini membutuhkan suatu acuan yang digunakan sebagai pedoman dan sumber referensi. Perpustakaan sebagai sumber informasi dapat menelusuri keterpakaian koleksi melalui daftar acuan yang dipergunakan oleh peneliti dalam penulisan karya ilmiah.

Sumber acuan yang digunakan peneliti dalam penulisan karya tulis ilmiah, dikelompokkan dalam tiga jenis publikasi yaitu rurnal, buku, dan prosiding. Dalam kurun waktu tahun 2016-2017 publikasi yang paling banyak digunakan sebagai acuan yaitu jurnal sebanyak $65 \%$, kemudian buku $22 \%$ serta prosiding 13\%. 9 (Tabel 2)

Tabel 2. Sumber sitiran yang digunakan pada tahun 2016-2017

\begin{tabular}{|c|c|c|c|c|c|c|c|}
\hline \multirow{2}{*}{ Tahun } & \multirow{2}{*}{\begin{tabular}{l} 
Jumlah \\
\cline { 3 - 7 }
\end{tabular}} & & \multicolumn{2}{|c|}{ Jurnal } & \multicolumn{2}{c|}{ Prosiding } & \multicolumn{2}{c|}{ Buku } \\
\cline { 3 - 7 } & & Jumlah & Persentase & Jumlah & Persentase & Jumlah & Persentase \\
\hline 2016 & 967 & 638 & $66 \%$ & 107 & $11 \%$ & 222 & $23 \%$ \\
\hline 2017 & 415 & 256 & $62 \%$ & 73 & $18 \%$ & 86 & $21 \%$ \\
\hline Total & $\mathbf{1 3 8 2}$ & $\mathbf{8 9 4}$ & $\mathbf{6 5 \%}$ & $\mathbf{1 8 0}$ & $\mathbf{1 3 \%}$ & $\mathbf{3 0 8}$ & $\mathbf{2 2 \%}$ \\
\hline
\end{tabular}

Tabel 3 Menunjukkan bahwa dari 894 sitiran, sumber sitiran dalam bentuk jurnal yang tersedia di perpustakaan BBRBLPP sebanyak $43 \%$ dan $57 \%$ merupakan publikasi yang tidak tersedia di perpustakaan BBRBLPP. Hal ini menunjukkan bahwa tingkat ketersediaan publikasi dalam bentuk jurnal di perpustakaan BBRBLPP berada dalam kategori sedang. Persentase sumber sitiran yang tersedia lebih 
rendah jika dibandingkan dengan yang tidak tersedia mengisyaratkan bahwa perpustakaan BBRBLPP harus lebih meningkatkan jumlah publikasi dalam bentuk jurnal sehingga bisa mempermudah penggunanya dalam mencari sumber referensi dalam penulisan karya tulis ilmiah

Tabel 3. Ketersediaan sumber sitiran dalam bentuk jurnal di perpustakaan BBRBLPP

\begin{tabular}{|c|c|c|c|c|c|}
\hline Tahun & Jumlah sitiran & \multicolumn{2}{|c|}{ Tersedia } & \multicolumn{2}{c|}{ Tidak tersedia } \\
\hline & & Jumlah & persentase & Jumlah & persentase \\
\hline 2016 & 638 & 319 & $50 \%$ & 319 & $50 \%$ \\
\hline 2017 & 256 & 68 & $27 \%$ & 188 & $73 \%$ \\
\hline Total & $\mathbf{8 9 4}$ & $\mathbf{3 8 7}$ & $\mathbf{4 3 \%}$ & $\mathbf{5 0 7}$ & $\mathbf{5 7 \%}$ \\
\hline
\end{tabular}

Publikasi dalam bentuk Prosiding yang digunakan sebagai referensi dalam penulisan KTI oleh peneliti BBRBLPP selama kurun waktu tahun 2016-2017 sebanyak 180 sitiran. (Tabel 4). Sitiran yang merupakan koleksi perpustakaan BBRBLPP sebanyak 151 sitiran (84\%) dan yang bukan merupakan koleksi atau tidak tersedia di perpustakaan BBRBLPP sebanyak 29 sitiran (16\%).

Hal ini menunjukkan bahwa tingkat ketersediaan prosiding di perpustakaan BBRBLPP berada dalam kategori sangat tinggi sehingga akan mempermudah penggunanya dalam pencarian sumber referensi dalam bentuk prosiding.

Tabel 4. Ketersediaan sumber sitiran dalam bentuk prosiding di perpustakaan BBRBLPP

\begin{tabular}{|c|c|c|c|c|c|}
\hline \multirow{2}{*}{ Tahun } & \multirow{2}{*}{ Jumlah sitiran } & \multicolumn{2}{|c|}{ Tersedia } & \multicolumn{2}{c|}{ Tidak tersedia } \\
\cline { 3 - 6 } & & Jumlah & persentase & Jumlah & persentase \\
\hline 2016 & 107 & 89 & $83 \%$ & 18 & $17 \%$ \\
\hline 2017 & 73 & 62 & $85 \%$ & 11 & $15 \%$ \\
\hline Total & $\mathbf{1 8 0}$ & $\mathbf{1 5 1}$ & $\mathbf{8 4} \%$ & $\mathbf{2 9}$ & $\mathbf{1 6 \%}$ \\
\hline
\end{tabular}

Publikasi dalam bentuk buku yang digunakan sebagai referensi dalam penulisan KTI oleh peneliti BBRBLPP selama kurun waktu tahun 2016-2017 sebanyak 308 sitiran (Tabel 5.). Sumber sitiran yang tersedia di perpustakaan BBRBLPP sebanyak 175 sitiran (57\%) dan yang bukan merupakan koleksi atau tidak tersedia di perpustakaan BBRBLPP sebanyak 133 sitiran 43\%. Hal ini menunjukkan bahwa tingkat ketersediaan buku sebagai sumber referensi di perpustakaan BBRBLPP berada dalam kategori sedang. Persentase sumber sitiran yang tersedia di perpustakaan BBRBLPP lebih tinggi jika dibandingkan dengan yang tidak tersedia. Hal ini berarti perpustakaan BBRBLPP cukup mampu menyediakan buku sebagai sumber referensi dalam penulisan Karya Tulis IImiah.

Tabel 5. Ketersediaan sumber sitiran dalam bentuk buku di perpustakaan BBRBLPP

\begin{tabular}{|c|c|c|c|c|c|}
\hline Tahun & Jumlah sitiran & \multicolumn{2}{|c|}{ Tersedia } & \multicolumn{2}{c|}{ Tidak tersedia } \\
\hline & & Jumlah & persentase & Jumlah & persentase \\
\hline 2016 & 222 & 142 & $64 \%$ & 80 & $36 \%$ \\
\hline 2017 & 86 & 33 & $38 \%$ & 53 & $62 \%$ \\
\hline Total & $\mathbf{3 0 8}$ & $\mathbf{1 7 5}$ & $\mathbf{5 7 \%}$ & $\mathbf{1 3 3}$ & $\mathbf{4 3} \%$ \\
\hline
\end{tabular}

Secara keseluruhan dari total 1382 sitiran selama kurun waktu tahu 2016 - 2017, sumber sitiran yang tersedia di perpustakaan BBRBLPP sebanyak $52 \%$ dan yang tidak tersedia sebanyak $48 \%$ (Tabel 6.). $\mathrm{Hal}$ ini berarti bahwa secara keseluruhan tingkat ketersediaan publikasi sebagai sumber referensi di perpustakaan BBRBLPP berada dalam kategori sedang. Meskipun demikian perlu dilakukan perbaikan dalam penyediaan koleksi karena perbedaan tingkat ketersediaan yang cukup tinggi antara jenis publikasi yang berbeda. Hal ini bisa dilihat 
Tabel 6. Ketersediaan sumber sitiran selama kurun waktu tahun 2016-2017 di perpustakaan BBRBLPP

\begin{tabular}{|c|c|c|c|c|}
\hline \multirow{2}{*}{ Jumlah sitiran } & \multicolumn{2}{|c|}{ Tersedia } & \multicolumn{2}{c|}{ Tidak tersedia } \\
\cline { 2 - 5 } & Jumlah & persentase & Jumlah & persentase \\
\hline 1382 & 713 & $\mathbf{5 2} \%$ & 669 & $\mathbf{4 8 \%}$ \\
\hline
\end{tabular}

\section{KESIMPULAN}

Berdasarkan hasil penghitungan tingkat ketersediaan koleksi perpustakaan BBRBLPP menunjukkan bahwa ketersediaan koleksi dalam bentuk jurnal dalam tingkat kategori sedang (43\%), prosiding dalam tingkat kategori sangat tinggi (84\%) serta ketersedian buku dalam tingkat kategori sedang (57\%). Secara keseluruhan ketersediaan koleksi perpustakaan dari analisa sitiran $\mathrm{KTI}$ peneliti BBRBLPP yang diterbitkan tahun 2016-2017 dapat dikategorikan sedang (52\%). Kondisi ini perlu menjadi perhatian, bahwa untuk mendukung kegiatan riset dan penulisan karya tulis ilmiah peneliti, perpustakaan masih membutuhkan tambahan koleksi yang sesuai dengan kebutuhan pengguna/peneliti.

\section{DAFTAR PUSTAKA}

Arikunto, Suharsimi. 2003. Prosedur Penelitian, Suatu Praktek. Jakarta:Bina Aksara.

Azrin, K. 2017.Pengaruh Ketersediaan Koleksi Perpustakaan Terhadap Minat Baca Siswa . http:/ /journal.unair.ac.id/download-fullpapersIn962caefbeOfull.pdf. Diakses tanggal 3 April 2018

Basuki, S. 1991. Pengantar IImu Perpustakaan. Jakarta: Gramedia Utama.

Broadus. R. N. 2007.. An investigation of the validity of bibliographic citations. Journal of the American Society for Information Science

Gafar, Abdul. 2017. Relevansi Ketersediaan Koleksi Perpustakaan Dengan Kebutuhan Informasi Pemustaka Pada Badan Perpustakaan Dan Arsip Daerah Kabupaten Kotabaru Kalimantan Selatan : Skripsi. http://repositori.uin-alauddin.ac.id/3319/ 1/ABDUL\%20GHAFFAR.pdf Diakses tanggal 12 April 2018

Hasugian, J.2005. Analisis Sitiran terhadap Disertasi Program Doktor (S-3) IImu Kedokteran Sekolah Pascasarjana Universitas Sumatera Utara . Pustaha: Jurnal Studi Perpustakaan dan Informasi, Vol.1, No.2, Desember 2005

puslit2.petra.ac.id/ejournal/index.php/pus/article/ download/17246/17198. Diakses tanggal 5 April 2018

Istiana, Purwani, and Sri Rohyanti Zulaikha. 2007. "Analisis Sitiran terhadap Skripsi Program studi Kartografi dan Penginderaan Jauh Fakultas Geografi Tahun 2005 dan Ketersediaannya di Perpustakaan Fakultas Geografi UGM." Jurnal Berkala IImu Pengetahuan dan Informasi 3 (6): 1-13.

Lasa HS. 2009. Kamus Kepustakawanan Indonesia. Yogyakarta: Pustaka Book Publisher.

Lasa, HS. 1990. Kamus Istilah Perpustakaan. Yogyakarta: Gadjah Mada University Press

Lasa HS. 2005. Manajemen Perpustakaan. Yogyakarta : Gama Media.

Perpustakaan Nasional RI. 1992. Pedoman Perpustakaan Khusus.Jakarta: Perpustakaan Nasional Republik Indonesia.

Perpustakaan Nasional RI. 2007. Undang-Undang Republik Indonesia Nomor 43 Tahun 2007 tentang Perpustakaan. Jakarta. Perpustakaan Nasional Republik Indonesia.

Sugiyono.(2010). MetodePenelitian Kuantitatif Kualitatif \& RND. Bandung : Alfabeta

Soeatminah, 1992.Perpustakaan, Kepustakawan dan Pustakawan, cet 1, Yogyakarta: Karnisius

Sujana, J.G. 2006. Mengoptimumkan Pengembangan Koleksi. Dalam Buletin Perpustakaan dan Informasi Bogor, Edisi 3 Oktober

Surata, I Gede. 1997. "Karakteristik Literatur yang Disitir dalam Skripsi Jurusan IImu Politik Fakultas IImu Sosial dan IImu Politik Universitas Hasanuddin dan Universitas Indonesia Tahun 1991-1995" (Tesis).Program Pascasarjana Universitas Indonesia, Jakarta.

Sutarno NS. 2006. Perpustakaan dan Masyarakat. Jakarta: Sagung Seto.

Yulia,Yuyu, Janti G Sujana dan Henny Windarti. Pengadaan Bahan Pustaka. Jakarta: Universitas Terbuka 1993 